\title{
Wilms' tumor suppressor gene mutations in girls with sporadic isolated steroid-resistant nephrotic syndrome
}

\author{
Y.H. Yang ${ }^{1 *}$, F. Zhao ${ }^{1 *}$, D.N. Feng ${ }^{1}$, J.J. Wang ${ }^{1}$, C.F. Wang ${ }^{1}$, J. Huang ${ }^{1}$, \\ X.J. Nie' ${ }^{1}$, G.Z. Xia ${ }^{1}$, G.M. Chen ${ }^{1}$ and Z.H. Yu ${ }^{1,2,3}$ \\ ${ }^{1}$ Department of Pediatrics, Fuzhou Dongfang Hospital, Fuzhou, Fujian, China \\ ${ }^{2}$ Department of Pediatrics, Fuzhou Clinical Medical College, \\ Fujian Medical University, Fuzhou, Fujian, China \\ ${ }^{3}$ Department of Pediatrics, Affiliated Dongfang Hospital, Xiamen University, \\ Fuzhou, Fujian, China \\ *These authors contributed equally to this study. \\ Corresponding author: Z.H. Yu \\ E-mail: zihuayu@vip.sina.com
}

Genet. Mol. Res. 12 (4): 6184-6191 (2013)

Received January 30, 2013

Accepted March 15, 2013

Published December 4, 2013

DOI http://dx.doi.org/10.4238/2013.December.4.5

\begin{abstract}
Mutations in the Wilms' tumor suppressor gene (WT1) can lead to syndromic forms of steroid-resistant nephrotic syndrome (SRNS) such as Denys-Drash or Frasier syndrome and can cause isolated SRNS. A mutation within WT1 is a frequent cause of sporadic isolated SRNS in girls. In a worldwide cohort of girls, the rate of occurrence was $10.8 \%$. Previous reports have indicated that in Chinese girls, the detection rate of WT1 mutations is $16.7 \%$ for early onset isolated nephrotic syndrome. The detection rate of WT1 mutations in Chinese girls with sporadic isolated SRNS is unknown. We examined WT1 mutations in 14 Chinese girls with sporadic isolated SRNS using polymerase chain reaction and direct sequencing and studied a control group of 38 boys with sporadic isolated SRNS. We identified a WT1 mutation in 1 of 14 (7.1\% detection rate) Chinese girls with sporadic
\end{abstract}


isolated SRNS. No mutations occurred in WT1 in the remaining 13 girls or the control group. Our investigation supports the necessity of genetic examination for mutations in WT1 in girls with sporadic isolated SRNS.

Key words: Steroid-resistant nephrotic syndrome; Mutation; Genetics; Wilms' tumor suppressor gene

\section{INTRODUCTION}

Idiopathic nephrotic syndrome (NS) is characterized by proteinuria, hypoalbuminemia, hyperlipidemia, and edema. It is the most common of the childhood glomerular diseases (Yu et al., 2005). Idiopathic NS is divided into steroid-sensitive NS and steroid-resistant NS (SRNS) based on patient response to steroid treatment. Most children with sporadic idiopathic NS respond to steroids and have a favorable long-term prognosis; however, $10-20 \%$ of patients do not respond and may progress to end-stage renal disease (Ruf et al., 2004a; Weber et al., 2004). Previous studies have demonstrated that mutations in the genes encoding podocyte proteins such as NPHS2 [Online Mendelian Inheritance in Man (OMIM) 604766] and Wilms' tumor suppressor gene (WT1; OMIM 607102) are responsible for SRNS (Boute et al., 2000; Mucha et al., 2006). NPHS2 has been mapped to chromosome 1q25-31, and the encoding podocin causes autosomal recessive SRNS (Boute et al., 2000). Mutations in NPHS2 are responsible for 45$55 \%$ of familial SRNS with autosomal recessive inheritance (Boute et al., 2000; Caridi et al., 2005). NPHS2 mutation is a frequent cause of sporadic SRNS, occurring in $10-28 \%$ of children with sporadic SRNS (Karle et al., 2002; Ruf et al., 2004a; Weber et al., 2004).

The WT1 gene, located on chromosome $11 \mathrm{p} 13$ and consisting of 10 exons, plays a crucial role in kidney and genital system development (Call et al., 1990; Haber et al., 1991; Bruening et al., 1992). Mutations in WT1 can lead to syndromic forms of SRNS such as Denys-Drash syndrome (OMIM 194080) (Pelletier et al., 1991) and Frasier syndrome (OMIM 136680) (Barbaux et al., 1997) and can cause isolated SRNS (Mucha et al., 2006). DenysDrash syndrome is characterized by the triad of infantile SRNS, ambiguous genitalia, and Wilms' tumor (Chernin et al., 2010). Frasier syndrome is characterized by the association of SRNS with male pseudohermaphroditism (Chernin et al., 2010). Isolated SRNS herein refers to SRNS without accompanying genital abnormalities, Wilms' tumor, ocular abnormalities, audiological abnormalities, or mental retardation. Although WT1 mutations have been found in only 3 boys with isolated NS (Takata et al., 2000; Chernin et al., 2010; Yang et al., 2013), they are a frequent cause of sporadic isolated SRNS in girls, occurring in $10.8 \%$ of girls in a worldwide cohort (Mucha et al., 2006). Previous studies have indicated that the screening of $W T 1$ exons 8 and 9 in patients with sporadic SRNS is sufficient to detect pathogenic WT1 mutations (Ruf et al., 2004b; Mucha et al., 2006).

Idiopathic NS is also the most frequent glomerular disease in Chinese children, of whom $20 \%$ with idiopathic NS show steroid resistance, a percentage similar to that in other countries (Yu et al., 2005). A previous study has reported a 16.7\% detection rate of WT1 mutations in Chinese girls with early onset isolated NS (Li et al., 2010).

To the best of our knowledge, the detection rate of WT1 mutations in Chinese girls with sporadic isolated SRNS remains unknown. Therefore, we examined mutations in exons 8 and 9 of WT1 in 14 Chinese girls with sporadic isolated SRNS using polymerase chain reaction (PCR) and direct sequencing. 


\section{MATERIAL AND METHODS}

\section{Subjects}

We enrolled patients $(\mathrm{N}=14)$ based on the following criteria: 1$)$ they were Chinese girls with no familial history of renal diseases and not children of consanguineous marriages; 2 ) they were older than 3 months and younger than 18 years at disease onset; 3 ) they were diagnosed with SRNS; 4) they did not develop Wilms' tumor based on renal ultrasound; 5) they lacked symmetrical deficits in sensitivity for high-frequency sounds on audiometry; 6) they lacked ocular lesions per ophthalmologic assessment; 7) they lacked post-infectious glomerulonephritis and systemic diseases per clinical and laboratory examinations; 8) they lacked mental retardation; and 9) they had no NPHS2 mutations. The control group comprised boys $(\mathrm{N}=38)$ with sporadic isolated SRNS. NS was diagnosed based on 24-h urinary protein excretion greater than $0.05 \mathrm{~g} / \mathrm{kg}$, with serum albumin less than $25 \mathrm{~g} / \mathrm{L}$. Steroid resistance was defined as the absence of remission after an initial 4 weeks of steroid therapy at a dose of 2 $\mathrm{mg} \cdot \mathrm{kg}^{-1} \cdot \mathrm{day}^{-1}$. We also studied, as controls, unrelated adult volunteers $(\mathrm{N}=50)$ with normal urinalyses. This study was approved by the ethics committee of Fuzhou Dongfang Hospital (China). Informed consent was obtained from patients or their parents.

\section{WT1 mutational analysis}

For genetic analysis of $W T 1$, genomic DNA was isolated from peripheral blood. Exons 8 and 9 of $W T 1$ were amplified using PCR. The primers used in the PCR amplification of exons 8 and 9 of $W T 1$ have been described previously (Mucha et al., 2006). Genomic DNA (50 ng) was subjected to 36 cycles of PCR amplification in a $25-\mu \mathrm{L}$ volume consisting of $1 \mu \mathrm{L}$ $5 \mu \mathrm{M}$ sense primer, $1 \mu \mathrm{L} 5 \mu \mathrm{M}$ antisense primer, $1.5 \mu \mathrm{L} 25 \mathrm{mM} \mathrm{MgCl}_{2}, 1 \mu \mathrm{L} 2.5 \mathrm{mM}$ deoxyribonucleotide triphosphates, and $0.125 \mu \mathrm{L} 5 \mathrm{U} / \mu \mathrm{L}$ Taq polymerase (Promega Corporation, Madison, WI, USA). The PCR products were visualized using 1.5\% (w/v) agarose gel electrophoresis. PCR amplicons were directly sequenced using an ABI 3730XL DNA Analyzer (Shanghai Invitrogen Biotechnology Co., Shanghai, China). Mutations were confirmed with sequencing in both directions and by repeated amplification and sequencing.

\section{Karyotype analysis or $\mathrm{Y}$ chromosome identification}

Karyotype analysis was performed on 3 patients. For patient 10, for whom karyotype analysis was not performed, the sex-determining region $\mathrm{Y}$ gene (a specific marker on the $\mathrm{Y}$ chromosome) was identified via amplification of SRY using PCR and confirmed with agarose gel electrophoresis (Harley et al., 2003). The primers used in the sex-determining region Y amplification reactions have been described previously (Tu et al., 2008).

\section{RESULTS}

\section{Clinical data}

All children ( $\mathrm{N}=52 ; 14$ girls, 38 boys) with sporadic isolated SRNS lacked genital 
abnormalities, Wilms' tumor, ocular abnormalities, audiological abnormalities, and mental retardation. In the 14 girls with sporadic isolated SRNS, age at onset was $5.7 \pm 3.5$ years (range, 1.2-11.6 years; Table 1). Renal biopsy was carried out on 5 female patients and revealed focal segmental glomerulosclerosis in 3 patients, diffuse mesangial sclerosis in 1 patient, and membranous nephropathy in 1 patient (see Table 1). In the control group, renal biopsy was carried out on 14 boys, revealing focal segmental glomerulosclerosis in 5 patients, mesangial proliferative glomerulonephritis in 4 patients, and minimal change NS in 5 patients.

Table 1. Clinical data for 14 female children with sporadic isolated steroid-resistant nephrotic syndrome.

\begin{tabular}{|c|c|c|c|c|c|c|c|c|c|}
\hline Patient & $\begin{array}{l}\text { Age of onset } \\
\text { (years) }\end{array}$ & $\mathrm{PU}$ (g/24 h) & $\mathrm{HU}$ & $\begin{array}{l}\text { Serum albumin } \\
(\mathrm{g} / \mathrm{L})\end{array}$ & $\begin{array}{l}\text { Creatinine } \\
(\mu \mathrm{M})\end{array}$ & $\begin{array}{l}\text { SUN } \\
(\mathrm{mM})\end{array}$ & $\begin{array}{c}\mathrm{GFR} \\
\left(\mathrm{mL} \cdot \mathrm{min}^{-1} \cdot 1.73 \mathrm{~m}^{-2}\right)\end{array}$ & Renal biopsy & Karyotype \\
\hline 1 & 1.2 & 1.810 & - & 19.6 & 25.0 & 4.30 & 111.00 & ND & ND \\
\hline 2 & 1.8 & 2.780 & + & 17.7 & 43.0 & 5.78 & $>120.00$ & ND & ND \\
\hline 3 & 2.3 & 1.780 & - & 8.8 & 162.0 & 18.70 & 53.34 & ND & ND \\
\hline 4 & 2.5 & 3.024 & + & 20.7 & 24.0 & 3.70 & 99.12 & ND & $46, \mathrm{XX}$ \\
\hline 5 & 2.8 & 0.828 & + & 14.7 & 30.0 & 4.35 & $>120.00$ & ND & ND \\
\hline 6 & 2.9 & 3.090 & - & 17.0 & 30.0 & 3.10 & ND & ND & ND \\
\hline 7 & 4.8 & 1.600 & + & 16.0 & 11.3 & 3.88 & $>120.00$ & FSGS & ND \\
\hline 8 & 6.6 & 2.317 & + & 12.0 & 48.0 & 5.50 & $>120.00$ & ND & ND \\
\hline 9 & 7.1 & 3.410 & + & 20.1 & 663.0 & 28.50 & 5.40 & FSGS & $46, \mathrm{XX}$ \\
\hline 10 & 8.1 & 2.046 & + & 17.0 & 66.0 & 5.60 & ND & ND & $46, X^{*}$ \\
\hline 11 & 8.3 & 1.700 & + & 22.3 & 56.0 & 6.30 & $>120.00$ & $\mathrm{MN}$ & $46, \mathrm{XX}$ \\
\hline 12 & 8.7 & 1.571 & + & 12.9 & 34.0 & 4.30 & $>120.00$ & ND & ND \\
\hline 13 & 10.8 & 2.380 & + & 18.0 & 555.0 & 34.90 & 9.60 & DMS & ND \\
\hline 14 & 11.6 & 5.420 & + & 24.0 & 51.0 & 5.50 & 118.80 & FSGS & ND \\
\hline
\end{tabular}

$\mathrm{PU}=$ proteinuria; $\mathrm{HU}=$ hematuria; $\mathrm{SUN}=$ serum urea nitrogen; GFR = glomerular filtration rate; $\mathrm{ND}=$ not determined; FSGS = focal segmental glomerulosclerosis; $\mathrm{MN}=$ membranous nephropathy; DMS $=$ diffuse mesangial sclerosis. *Y chromosome identification showed no Y chromosome.

Patient 10 initially presented with transient eyelid edema and massive proteinuria at 8.1 years old; eyelid edema subsided without any treatment. She was hospitalized at 8.5 years with severe eyelid edema and persistent proteinuria within the nephrotic range. Physical examination revealed eyelid edema and normal female external genitalia. Blood pressure was normal, and a urine dipstick revealed 3+ albumin. Her 24-h proteinuria was $2.046 \mathrm{~g}$, and serum albumin was $17 \mathrm{~g} / \mathrm{L}$. Serum cholesterol was $13.55 \mathrm{mM}$, serum creatinine was $66 \mu \mathrm{M}$, and a renal ultrasound was normal. She did not respond to a 6 -week course of $2 \mathrm{mg} \cdot \mathrm{kg}^{-1} \cdot \mathrm{day}^{-1}$ prednisone. A renal biopsy was refused by her parents, and she was diagnosed with isolated SRNS.

\section{WT1 mutational analysis}

The $W T 1$ mutation, IVS9 $+5 \mathrm{G}>\mathrm{A}$, was identified in patient 10 but not in the 50 normal controls. No mutations in $W T 1$ were found in the other 13 girls or in the control group of 38 boys. Therefore, the detection rate of $W T 1$ mutations in girls with sporadic isolated SRNS was $7.1 \%(1 / 14)$.

\section{Karyotype analysis}

Karyotype analysis, or Y chromosome identification, showed 46 XX karyotypes in 4 patients (see Table 1). 


\section{DISCUSSION}

In this study, we found that a heterozygous mutation (IVS9+5G>A) in WT1 was associated with the occurrence of sporadic isolated SRNS in 1 of 14 Chinese girls. Our results support the necessity for genetic examination for WT1 mutations in Chinese girls with sporadic isolated SRNS.

The $W T 1$ variant IVS9+5G>A in patient 10 was absent in the 50 normal controls. Previous studies have reported that the IVS9+5G $>$ A mutation in WT1 can cause Denys-Drash and Frasier syndromes and also lead to isolated SRNS (Mucha et al., 2006; Aucella et al., 2006; Löwik et al., 2008; Chernin et al., 2010; Li et al., 2010; Gellermann et al., 2010; Megremis et al., 2011). A total of 11 girls had isolated SRNS caused by the IVS9+5G $>$ A WT1 mutation (Table 2). Their age at onset ranged from $0.25-8.5$ years (average 3.5 years). Patient 10 presented with SRNS at 8.1 years. She had a normal female phenotype and lacked a Y chromosome. No tumor was identified using renal ultrasound, and therefore she was diagnosed with isolated SRNS. All of her clinical features were similar to those observed in patients with the IVS9+5G>A WT1 mutation (Aucella et al., 2006; Löwik et al., 2008; Chernin et al., 2010). We considered IVS9+5G>A to be responsible for the clinical manifestations of patient 10 .

\begin{tabular}{|c|c|c|c|c|c|}
\hline Patients & Genotype/phenotype & Age of onset (years) & Renal biopsy & ESRD (years after onset) & References \\
\hline 4 & $\mathrm{~F} / \mathrm{F}$ & 2.0 & FSGS & $\mathrm{N}(17.0)$ & Megremis et al., 2011 \\
\hline IE & $\mathrm{F} / \mathrm{F}$ & 6.0 & FSGS & $Y(4.0)$ & Aucella et al., 2006 \\
\hline F921 & $\mathrm{F} / \mathrm{F}$ & 2.3 & FSGS & $Y(5.8)$ & Mucha et al., 2006 \\
\hline F1280 & $\mathrm{F} / \mathrm{F}$ & 8.1 & FSGS & $\mathrm{N}(8.1)$ & Chernin et al., 2010 \\
\hline A562 & $\mathrm{F} / \mathrm{F}$ & 5.7 & MCNS & $\mathrm{N}(5.7)$ & Chernin et al., 2010 \\
\hline A2074 & $\mathrm{F} / \mathrm{F}$ & 3.1 & FSGS & $\mathrm{N}(3.1)$ & Chernin et al., 2010 \\
\hline A 2328 & $\mathrm{~F} / \mathrm{F}$ & 0.9 & DMS & $\mathrm{N}(0.9)$ & Chernin et al., 2010 \\
\hline $\mathrm{P} 1$ & $\mathrm{~F} / \mathrm{F}$ & 0.3 & FSGS & $Y(2.7)$ & Li et al., 2010 \\
\hline $\mathrm{P} 4$ & $\mathrm{~F} / \mathrm{F}$ & 1.0 & ND & $\mathrm{Y}(0.3)$ & Li et al., 2010 \\
\hline $\mathrm{P} 1$ & $\mathrm{~F} / \mathrm{F}$ & 1.0 & FSGS & $\mathrm{N}(15.9)$ & Gellermann et al., 2011 \\
\hline P3 & $\mathrm{F} / \mathrm{F}$ & 8.5 & FSGS & $\mathrm{Y}(6.0)$ & Löwik et al., 2008 \\
\hline
\end{tabular}

$\mathrm{ESRD}=$ end-stage renal disease; $\mathrm{F}=$ female; $\mathrm{FSGS}=$ focal segmental glomerulosclerosis; $\mathrm{MCNS}=$ minimal change nephrotic syndrome; $\mathrm{DMS}=$ diffuse mesangial sclerosis; $\mathrm{ND}=$ not determined; $\mathrm{Y}=$ yes; $\mathrm{N}=$ no.

No significant differences occurred among the detection rates of WT1 mutations in girls with sporadic isolated SRNS from various ethnic groups (Table 3). In our study, the detection rate of WT1 mutations in girls with sporadic isolated SRNS was 7.1\% (1/14). Li et al. (2010) have screened for WT1 mutations in 12 Chinese girls with early onset isolated NS and identified mutations in 2 of the patients. Therefore, the rate of WT1 mutations in girls with early onset isolated NS was $16.7 \%$ ( $\mathrm{Li}$ et al., 2010), a rate higher than that determined in our study. However, Li et al. (2010) studied girls with onset age greater than 3 years as the control group, with no WT1 mutations detected in these patients. When the results of both the 12 girls with early onset NS and the 12 girls with onset age more than 3 years were combined, the detection rate of $W T 1$ mutants was $8.7 \%(2 / 24)$, a result comparable to the findings of the present study. Ruf et al. (2004b) have examined WT1 mutations in 54 girls from central Europe, Turkey, and India with sporadic isolated SRNS. The authors identified WT1 mutations in 4 patients (7.4\%). Mucha et al. (2006) screened for WT1 mutations in 74 girls with central 
European, Turkish, African-American, Hispanic, or Asian backgrounds and with sporadic isolated SRNS. They detected WT1 mutations in 8 patients (10.8\%). Aucella et al. (2006) have examined WT1 mutations in 30 Italian girls with sporadic isolated SRNS and found WT1 mutations in 2 female patients (6.7\%). Cho et al. (2008) have examined WT1 mutations in 37 Korean girls with sporadic isolated SRNS and identified a WT1 mutation in 1 patient (2.7\%). When the results of our study and those of previous studies were combined, the detection rate of WT1 mutants in girls with sporadic isolated SRNS was 7.7\% (18/233) (Ruf et al., 2004b; Aucella et al., 2006; Mucha et al., 2006; Cho et al., 2008; Li et al., 2010).

Table 3. Detection rates of $W T 1$ mutations in children with sporadic isolated steroid-resistant nephrotic syndrome.

\begin{tabular}{|c|c|c|c|}
\hline Ethnic background & Number of patients (male:female) & Detection rate of $W T 1$ mutations & References \\
\hline Worldwide cohort & $111(57: 54)$ & $\begin{array}{l}\text { Male: } 0 \%(0 / 57) \\
\text { Female: } 7.4 \% *(4 / 54)\end{array}$ & Ruf et al., 2004b \\
\hline Worldwide cohort & $158(84: 74)$ & $\begin{array}{l}\text { Male: } 0 \%(0 / 84) \\
\text { Female: } 10.8 \% *(8 / 74)\end{array}$ & Mucha et al., 2006 \\
\hline Italian & $62(32: 30)$ & $\begin{array}{l}\text { Male: } 0 \%(0 / 32) \\
\text { Female: } 6.7 \% *(2 / 30)\end{array}$ & Aucella et al., 2006 \\
\hline Korean & $67(30: 37)$ & $\begin{array}{l}\text { Male: } 0 \%(0 / 30) \\
\text { Female: } 2.7 \% *(1 / 37)\end{array}$ & Cho et al., 2008 \\
\hline Chinese & $67(43: 24)$ & $\begin{array}{l}\text { Male: } 0 \%(0 / 43) \\
\text { Female: } 8.3 \% *(2 / 24 \dagger)\end{array}$ & Li et al., 2010 \\
\hline Chinese & $52(38: 14)$ & $\begin{array}{l}\text { Male: } 0 \%(0 / 38) \\
\text { Female: } 7.1 \% *(1 / 14)\end{array}$ & Present study \\
\hline
\end{tabular}

*No significant difference among the detection rates of WT1 mutations in the six groups, as analyzed by the chisquared test $\left(\chi^{2}=2.352, \mathrm{P}=0.807\right)$. Includes 12 female patients with early-onset (within 3 years of age) nephrotic syndrome and 12 female patients with an onset age greater than 3 year.

We were unable to identify WT1 mutations in the phenotypically normal 38 male patients used as the control group. Previous large studies have also reported that no phenotypically normal boys without genitourinary malformations and Wilms' tumor display mutations within WT1 (Ruf et al., 2004b; Aucella et al., 2006; Mucha et al., 2006; Cho et al., 2008; Li et al., 2010; Mbarek et al., 2011). Only 3 boys with isolated NS have reportedly displayed WT1 mutations in studies (Takata et al., 2000; Chernin et al., 2010; Yang et al., 2013). Takata et al. (2000) have reported that the cause of nephropathy in a 2-year-old boy lacking genital abnormalities and Wilms' tumor was the R312Q WT1 mutation. He rapidly progressed to chronic kidney disease stage 5; his karyotype was 46, XY. Chernin et al. (2010) have reported that isolated NS in a 1.5-year-old boy was caused by the R394W WT1 mutation. He rapidly progressed to renal failure at 1.7 years; his karyotype was $46, \mathrm{XY}$. We have recently reported that isolated NS in a 6.3-year-old boy was caused by the K351E WT1 mutation. He rapidly progressed to end-stage renal disease; his karyotype was 46, XY (Yang et al., 2013). Our results further support that mutational analysis of WT1 is not regularly recommended for boys with sporadic isolated SRNS. Recently, we identified an identical de novo heterozygous WT1 mutation, R394W, in a pair of Chinese female monozygotic twins. They presented with incomplete Denys-Drash syndrome and isolated SRNS (Yu et al., 2012).

In conclusion, we identified a WT1 mutation in 1 of 14 Chinese girls with sporadic isolated SRNS, indicative of a $7.1 \%$ detection rate for $W T 1$ mutations in these individuals. Our investigation supports the necessity of genetic examination for WT1 mutations in Chinese girls with sporadic isolated SRNS. 


\section{ACKNOWLEDGMENTS}

We thank the patients and their families for their participation in this study, and Professor Jie Ding for her help with the grants. This study was supported by grants from National Nature Science Foundation of China (\#81270766) and the Nature Science Foundation of Fujian Province of China (\#2012J01405).

\section{REFERENCES}

Aucella F, Bisceglia L, De Bonis P, Gigante M, et al. (2006). WT1 mutations in nephrotic syndrome revisited. High prevalence in young girls, associations and renal phenotypes. Pediatr. Nephrol. 21: 1393-1398.

Barbaux S, Niaudet P, Gubler MC, Grunfeld JP, et al. (1997). Donor splice-site mutations in WT1 are responsible for Frasier syndrome. Nat. Genet. 17: 467-470.

Boute N, Gribouval O, Roselli S, Benessy F, et al. (2000). NPHS2, encoding the glomerular protein podocin, is mutated in autosomal recessive steroid-resistant nephrotic syndrome. Nat. Genet. 24: 349-354.

Bruening W, Bardeesy N, Silverman BL, Cohn RA, et al. (1992). Germline intronic and exonic mutations in the Wilms' tumour gene (WTI) affecting urogenital development. Nat. Genet. 1: 144-148.

Call KM, Glaser T, Ito CY, Buckler AJ, et al. (1990). Isolation and characterization of a zinc finger polypeptide gene at the human chromosome 11 Wilms' tumor locus. Cell 60: 509-520.

Caridi G, Perfumo F and Ghiggeri GM (2005). NPHS2 (Podocin) mutations in nephrotic syndrome. Clinical spectrum and fine mechanisms. Pediatr. Res. 57: 54R-61R.

Chernin G, Vega-Warner V, Schoeb DS, Heeringa SF, et al. (2010). Genotype/phenotype correlation in nephrotic syndrome caused by WT1 mutations. Clin. J. Am. Soc. Nephrol. 5: 1655-1662.

Cho HY, Lee JH, Choi HJ, Lee BH, et al. (2008). WT1 and NPHS2 mutations in Korean children with steroid-resistant nephrotic syndrome. Pediatr. Nephrol. 23: 63-70.

Gellermann J, Stefanidis CJ, Mitsioni A and Querfeld U (2010). Successful treatment of steroid-resistant nephrotic syndrome associated with WT1 mutations. Pediatr. Nephrol. 25: 1285-1289.

Haber DA, Sohn RL, Buckler AJ, Pelletier J, et al. (1991). Alternative splicing and genomic structure of the Wilms tumor gene WT1. Proc. Natl. Acad. Sci. U. S. A. 88: 9618-9622.

Harley VR, Clarkson MJ and Argentaro A (2003). The molecular action and regulation of the testis-determining factors, SRY (sex-determining region on the Y chromosome) and SOX9 [SRY-related high-mobility group (HMG) box 9]. Endocr. Rev. 24: 466-487.

Karle SM, Uetz B, Ronner V, Glaeser L, et al. (2002). Novel mutations in NPHS2 detected in both familial and sporadic steroid-resistant nephrotic syndrome. J. Am. Soc. Nephrol. 13: 388-393.

Li J, Ding J, Zhao D, Yu Z, et al. (2010). WT1 gene mutations in Chinese children with early onset nephrotic syndrome. Pediatr. Res. 68: 155-158.

Löwik M, Levtchenko E, Westra D, Groenen P, et al. (2008). Bigenic heterozygosity and the development of steroidresistant focal segmental glomerulosclerosis. Nephrol. Dial. Transplant 23: 3146-3151.

Mbarek IB, Abroug S, Omezzine A, Pawtowski A, et al. (2011). Novel mutations in steroid-resistant nephrotic syndrome diagnosed in Tunisian children. Pediatr. Nephrol. 26: 241-249.

Megremis S, Mitsioni A, Fylaktou I, Tzeli SK, et al. (2011). Broad and unexpected phenotypic expression in Greek children with steroid-resistant nephrotic syndrome due to mutations in the Wilms' tumor 1 (WTI) gene. Eur. $J$. Pediatr. 170: 1529-1534.

Mucha B, Ozaltin F, Hinkes BG, Hasselbacher K, et al. (2006). Mutations in the Wilms' tumor 1 gene cause isolated steroid resistant nephrotic syndrome and occur in exons 8 and 9. Pediatr. Res. 59: 325-331.

Pelletier J, Bruening W, Kashtan CE, Mauer SM, et al. (1991). Germline mutations in the Wilms' tumor suppressor gene are associated with abnormal urogenital development in Denys-Drash syndrome. Cell 67: 437-447.

Ruf RG, Lichtenberger A, Karle SM, Haas JP, et al. (2004a). Patients with mutations in NPHS2 (podocin) do not respond to standard steroid treatment of nephrotic syndrome. J. Am. Soc. Nephrol. 15: 722-732.

Ruf RG, Schultheiss M, Lichtenberger A, Karle SM, et al. (2004b). Prevalence of WT1 mutations in a large cohort of patients with steroid-resistant and steroid-sensitive nephrotic syndrome. Kidney Int. 66: 564-570.

Takata A, Kikuchi H, Fukuzawa R, Ito S, et al. (2000). Constitutional WT1 correlate with clinical features in children with progressive nephropathy. J. Med. Genet. 37: 698-701.

Tu XO, Lan FU and Zhu ZO (2008). Positioning analysis of the Yq11 deletion in a patient with azoospermia. Zhonghua 
Yi. Xue. Yi. Chuan Xue. Za Zhi. 25: 203-205.

Weber S, Gribouval O, Esquivel EL, Moriniere V, et al. (2004). NPHS2 mutation analysis shows genetic heterogeneity of steroid-resistant nephrotic syndrome and low post-transplant recurrence. Kidney Int. 66: 571-579.

Yang Y, Feng D, Huang J, Nie X, et al. (2013). A child with isolated nephrotic syndrome and WT1 mutation presenting as a 46, XY phenotypic male. Eur. J. Pediatr. 172: 127-129.

Yu Z, Yang Y and Feng D (2012). Discordant phenotypes in monozygotic twins with identical de novo WT1 mutation. Clin. Kidney J. 5: 221-222.

Yu Z, Ding J, Huang J, Yao Y, et al. (2005). Mutations in NPHS2 in sporadic steroid-resistant nephrotic syndrome in Chinese children. Nephrol. Dial. Transplant 20: 902-908. 